\title{
ENTREVISTA COM HELDER MACEDO, PARTE II $^{1}$
}

\author{
Ana Cristina Joaquim ${ }^{2}$ \\ Rui Daniel Nascimento Sousa ${ }^{3}$ \\ Sofia Santos ${ }^{4}$
}

1- [ACJ]: Sobre a dimensão política da sua atuação em sentido amplo, há mais de uma evidência (embora de modo heterodoxo...): em A Utopia da Negação, você diz que "O que o Café Gelo da segunda metade dos anos 50 pode ter significado certamente não é definível em termos políticos partidários. Mesmo quando (ou sobretudo quando), por exemplo, o Herberto Helder e eu nos encontrámos envolvidos, em 1958, numa desarrumada tentativa de golpe revolucionário que teria metido armas... se tivesse acontecido." (MACEDO, Helder. "A utopia da negação", Arte \& Utopia (Ed Margarida Acciaiuoli, Ana Duarte Rodrigues, Maria João Castro, Paula André, Paulo Simões Rodrigues) CHAIA; DINÂMICA’CET-IUL; FCSH, Lisboa, 2013 (pp. 237244), p. 241); em Partes de África (1999) o traço biográfico-memorialístico convive com a ficção num empenho de problematizar as relações entre Portugal e África em meados do século XX. Fato de relevância, ainda, foi ter assumido a Secretaria de Estado da Cultura, em 1979, quando do seu retorno a Portugal, depois de longo exílio decorrente da ditadura salazarista. Você acredita que seria possível estabelecer um eixo que integre esses eventos mencionados?

[HM]: Não ser definível em termos políticos partidários não é o mesmo que não ser politicamente definível. Creio que os jovens associados ao Gelo na segunda metade dos anos 50 tinham (tínhamos) em comum sermos contra as estruturas repressivas vigentes. Talvez suspeitássemos (pelo menos alguns de nós) que vinculações partidárias poderiam ser (ou virem a ser) novas formas de repressão. Mas isso não nos impediu de colaborarmos com os grupos políticos na oposição ao regime em acções concretas. Tínhamos um inimigo comum, que nos unia em recusa. Foi o que aconteceu nessa "desarrumada tentativa de golpe revolucionário". Note também que, como mostrei no prefácio às Sobras Completas do José Manuel Simões (recentemente publicado na Editora Abysmo) o Manuel de Castro pensou a certa altura em participar, com mais alguns de nós, em ações armadas contra o regime. Quanto à minha participação em governos depois do 25 de Abril: foram dois, o V Governo Provisório, em 1975, quando aceitei ser nomeado Diretor Geral dos Espetáculos, e o V Governo Constitucional, em

\footnotetext{
1 A primeira parte da entrevista foi publicada em: Revista Desassossego, n. 16, 15/JUN/2016 (Disponível em: http://www.revistas.usp.br/desassossego/article/view/112710/116999)

${ }^{2}$ Doutora em Letras pela Universidade de São Paulo (2016).

${ }^{3}$ Doutorando em Letras pela Universidade de Lisboa.

4 Doutoranda em Letras pela Universidade de Lisboa.
} 


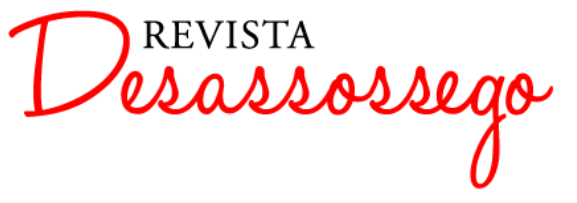

1979, quando fui Secretário de Estado da Cultura. Esses dois governos (liderados por pessoas tão diferentes como foram Vasco Gonçalves, aparentemente associado ao Partido Comunista, e Maria de Lourdes Pintasilgo, aparentemente associada a uma militância socialista cristã) tinham em comum uma espécie de marginalidade que me atraiu. Não eram governos viáveis em termos institucionais "normais". Foram ambas afirmações de princípios fundamentais manifestados em recusas por mim partilhadas. Esse será talvez o "eixo" que você sugere. Como você pode imaginar, eu teria podido ter uma carreira política depois de ter passado por esses governos. Fui convidado para me candidatar a deputado por três partidos políticos, mas recusei. A recusa é o eixo.

2- [RDNS]: Nos últimos anos, o Helder tem dado um importante contributo quanto à construção de uma imagem mais plural e heterogénea do que foi e não foi o Grupo do Café Gelo, que ainda não é suficientemente conhecido, não só em Portugal como no Brasil. Como descreveria o essencial das várias etapas do que conheceu desse grupo, não só por ter pertencido ao quotidiano do Gelo em Portugal como também por ter mantido, ao longo de décadas, contactos regulares com diferentes intervenientes, tanto os que ficaram em Portugal como os que levaram o espírito na sua busca de liberdade no estrangeiro?

[HM]: Creio que houve três fases, como manifestações diferenciadas, mas complementares. A primeira associada ao que pode ser entendido como o núcleo fundador, se alguma coisa foi fundada e não aconteceu apenas por acidentes circunstancias. As outras duas são mais ou menos simultâneas e manifestam respectivamente a continuidade desse espírito inicial entre os que saíram de Portugal e os que lá permaneceram. Entre estes houve uma crescente submissão a um surrealismo de escola, liderado pela personalidade carismática do Mário Cesariny. Como já referi num texto em que descrevi a experiência vivida nessa época como uma "utopia da negação", os encontros de amigos (e nem sempre assim tão amigos) que decorreram no Café Gelo começaram por ser uma convergência de recusas, um modo diferenciado de lidarmos com esse "tempo de fantasmas" (na apta caracterização do Alexandres O’Neill), onde as pessoas se habituavam a que, na aparência, não acontecesse nada. Apanhados entre a revolta silenciada e a resignação pactuante, nós - os que nos encontrávamos no Gelo e que de algum modo fôramos criados no mesmo ambiente que a todos oprimia - tínhamos sobretudo uma atitude de recusa em comum, uma partilhada vontade de quebrar amarras, procurando na dissidência contra o que não queríamos os caminhos para o espaço livre daquilo que poderíamos talvez querer. Fazíamos, portanto, da recusa das normas estabelecidas a nossa única norma, questionando sistematicamente os valores estabelecidos. Sentíamo-nos a viver num mundo às avessas de 


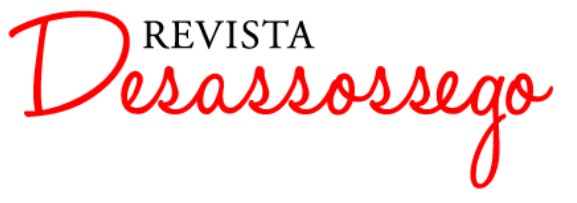

valores em que nos conseguíssemos reconhecer. A única via era portanto virar do avesso aquilo que já era o avesso de qualquer coisa. Foi dentro desse espírito libertário que acolhemos com entusiasmo alguns escorraçados mais velhos, como o Mário Cesariny, que a moralidade oficial oprimia sistematicamente e cuja poesia já então conhecíamos e admirávamos. Ou o profissional do abjeccionismo que foi o Luís Pacheco. Ou o velho Raul Leal, sobrevivente dos tempos de Orpheu e da abjecção que viveu como poucos e que continuou a viver até ao fim, em permanente furor mistico e libertário. Depois alguns dos que por lá ficaram aderiram a modelos preexistentes, a rótulos como os de surrealistas, ou abjecionistas, ou outros ismos prontos a vestir, e até, politicamente, de comunistas. Antes do 25 de Abril, o Partido Comunista representava uma forma clandestina de dissidência. A partir daí passou a ser parte legítima de um sistema político-democrático. Acho muito bem, mas isso é outro assunto. Se eu quisesse ser maldoso, diria que alguns (não todos...) sobreviventes do Gelo academizaram a dissidência. $\mathrm{Ou}$ deram-lhe sobretudo uma expressão literária, aliás nalguns casos meritória, como o António José Forte, o Virgílio Martinho e porventura aquele que de todos nós (incluindo o Cesariny) mais sabia de surrealismo, o Ernesto Sampaio. Também há que não esquecer alguns mais jovens, como o António Barahona, que encontrou no misticismo islâmico a sua via paralela à da dissidência. Entretanto, sobretudo na primeira década dos anos 60, outros tinham procurado ir lá fora respirar o ar que por cá faltava e foram-se dispersando, sem nunca perderem contacto, e dando início a outros projectos que prolongaram o espírito do Gelo, como por exemplo na revista KWY. Entre eles, o Herberto Helder, o Manuel de Castro, o Gonçalo Duarte, o José Escada, o João Vieira, o Costa Pinheiro, René Betholo e a Lourdes Castro, o João Rodrigues, o José Sá Caetano, o José Manuel Simões, eu próprio. E até, embora mais indirectamente, o meu amigo de infância, o filósofo Fernando Gil. Tragicamente, nem todos se aguentaram. Por exemplo o João Rodrigues. Ou, num suicídio mais lento, o Manuel de Castro. Ou o José Sebag, que simbolicamente se afogou com os poemas que atirou ao rio. É difícil fazer a contabilidade de tudo aquilo que foi, que dizem que foi, ou que poderia ter sido e nunca chegou a ser o famigerado Grupo do Café Gelo. Quanto a mim, quem melhor nos representa é alguém que nunca existiu: o Luís Garcia de Medeiros, um poeta inventado por mim, pelo Herberto Helder e pelo José Sebag, em três noites de desesperada bebedeira. Tanto assim que aproveitei a sua inexistência como personagem do meu romance Partes de África. E a sua obra completa foi depois publicada pelo Vítor Silva Tavares, na \&etc,, com a assinatura do Autor numa pedra, testemunhos fidedignos do Herberto Helder e meus, um telegrama do defunto José Sebag enviado de um Café Gelo que houvesse no Outro Mundo, e capa do João Vieira. 


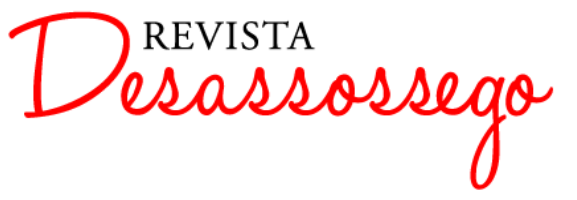

3- [SS]: Luiz Pacheco foi um dos muitos autores que frequentou o Café Gelo e que escreveu sobre o grupo que celebrizou o espaço. Em sua opinião, em que medida ele se inscreve nesse contexto? Aproximá-lo-ia do Surrealismo, como alguns críticos procuram fazer?

[HM]: Claro que o Luiz Pacheco foi um dos do Gelo. O que unificava a diversidade do Gelo era a dissidência. O Pacheco era (e manteve-se até ao fim) um dissidente. A sua identificação com o surrealismo é justificável na medida em que o surrealismo pode ser identificado com dissidência. Mas talvez mais como uma atitude ética (ou, no caso dele, antiética) do que estética. Creio que isso é evidente tanto no modo como viveu quanto no que escreveu. Inclusive nas suas críticas ao Mário Cesariny.

4- [SS]: São conhecidas as controvérsias em torno de Luiz Pacheco, enquanto personalidade e autor. Tendo em conta a insistente proscrição a que foi votado por alguns críticos, considera-o um autor relevante para a vanguarda do século XX? De que modo terá ele contribuiu para a literatura portuguesa pós-modernista?

[HM]: O Luiz Pacheco foi quem mais insistentemente votou o Luiz Pacheco à proscrição. Era o seu modo de ser e de agir. Era também um modo de ser autor de si próprio. Cultivando um narcísico nojo por si próprio. E portanto manifestado em nojo por tudo e por todos. É interessante que ele esteja sendo recuperado - e mitificado - pelas atuais gerações mais ou menos caracterizáveis como "pós-modernas". Onde as ideologias definharam numa indefinida atitude de "vale tudo". No tempo dele não valia tudo. Havia perigo em ser e em agir como ele foi e agiu. Creio que há uma perversa neutralização daquilo que ele representou nesta póstuma e algo tardia - recuperação literária do Luiz Pacheco. Um morto não morde. Enquanto vivo ele mordeu sempre. Começando por si próprio. Enquanto vivo fedia mais do que depois de morto. Resta saber se essa recuperação é um contributo para a literatura pós-modernista ou se é uma neutralização pós-modernista do Pacheco como apenas literatura. Retirando o fedor do seu corpo vivo. Impunemente.

5- [ACJ]: No quinto episódio da série "Arquipélago" (vídeo disponibilizado no seguinte endereço: https://www.youtube.com/watch?v=YhB4kUk2-FI\&feature=share), ao expor o seu testemunho - que é também uma lúcida análise - acerca do Café Gelo, você discorre da seguinte maneira: "Dizer ou presumir que o Herberto Helder é surrealista... não é nada, pá! O Manuel de Castro é surrealista? Não é! Não é. É claro que adotou todas as técnicas que pode haver do surrealismo, como do futurismo, como do...! Nós líamos! Nós líamos. Experimentávamos e fazíamos as coisas. Odeio rótulos. Rótulos é uma forma de neutralização, é uma forma de restrição: fica arrumado...! É transformar essa gente em movimentos literários: não somos. Não 


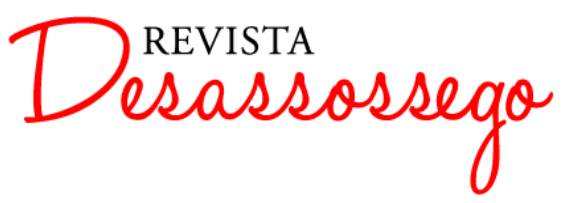

fomos.”. Eu tenho minhas próprias justificativas para considerar que você, o Herberto Helder e o Manuel de Castro não são surrealistas, entretanto eu gostaria de saber, se, para além da recusa dos rótulos, há algo mais que lhe sirva como parâmetro que justifique o "não-surrealismo" de vocês todos.

[HM]: Bom, alguns dos companheiros do Gelo eram, ou tornaram-se, assumidamente surrealistas. Por exemplo o Ernesto Sampaio, o António José Forte e o Virgílio Martinho. Além obviamente, do Mário Cesariny. Quero apenas acentuar que outros (como o Herberto, o Manuel e eu próprio) não são definíveis nesses termos. Portanto, é necessário caracterizar o Gelo em termos que incluam a diferença. A diferença que nos aliava.

6- [RDNS]: Publicou-se recentemente o livro Sobras Completas, de José Manuel Simões, um dos mais singulares indivíduos do contexto do Gelo, quase completamente esquecido. O que nos poderia dizer da sua importância, tanto enquanto companheiro de diferentes momentos como enquanto figura profundamente ligada à literatura, nas suas distintas vertentes?

[HM]: Olhe, já contei como foi e como não foi no prefácio às Sobras Completas. Digo lá, entre outras coisas, que o José Manuel Simões terá sido o grande exemplo que todos nós encontrámos no Gelo e que foi quem mais longe levou a experiência de não ser um escritor com uma obra mas de ter sido a obra que poderia ter escrito. A sua vida é que foi a sua verdadeira obra. Completou-a quando morreu. O que deixou escrito, e que me confiou pouco antes de morrer, são as "sobras" só ironicamente caracterizáveis "completas" dessa obra muito mais decisiva que qualquer escrito. Foi em 1998, no nosso último encontro, que, com aquela autoironia dos que resistem sempre, ele me entregou os poemas que saíram há pouco tempo num livrinho editado pela abysmo. A sua presença foi sempre fundamental, verdadeiramente fundadora, onde quer que se encontrasse. Foi-o enquanto esteve no Café Gelo e continuou a sê-lo depois de abandonar o Portugal irrespirável em que esse grupo, que não foi propriamente grupo, germinou. Não por acaso, foi a ele que o Manuel de Castro dedicou o seu primeiro livro, Paralelo W, e foi ele quem sugeriu ao Herberto Helder o título para o seu primeiro grande poema, $O$ Amor em Visita. Traduziu coisas importantes: o Stendhal, o Sade... Fez em França trabalhos pioneiros sobre Pessoa, com o Fernando Gil. Foi colaborador anónimo da revista Ruedo Iberico, que articulava a resistência política espanhola e portuguesa. Ainda há certamente outras "sobras" por descobrir, no espólio de outros amigos, como o João Vieira, que o seu filho, o também pintor Manuel João Vieira, tem estado a organizar. Em suma: ainda há muito por dizer sobre o José Manuel Simões. 